\title{
The significance of a nineteenth century definition in the era of genomics: linitis plastica
}

\author{
Annamaria Agnes ${ }^{1}$, Jeannelyn S. Estrella² and Brian Badgwell ${ }^{1 *}$
}

\begin{abstract}
Background: Linitis plastica due to gastric adenocarcinoma is a condition with a long history, but still lacks a standardized definition and is commonly confused with Borrmann type IV, Lauren diffuse, and signet-cell type gastric cancer. The absence of a clear definition is a problem when investigating its biological characteristics and role as a possible independent factor for prognosis. Nevertheless, the biological behavior for linitis plastica, which is unique, may be valuable in risk stratification and have implications for treatment. A definition of linitis plastica based on molecular or genomic criteria could represent a useful starting point for investigating new targeted therapies.

Main body: This literature review of linitis plastica will focus on the current classifications for gastric cancer, illustrating how the concept of linitis plastica relates to them in most cases and identifying a clear and reproducible definition. Moreover, the review will highlight the diagnostic challenges associated with linitis plastica, its prognostic implications, and the therapeutic options available. Future perspectives for its management are also addressed.

Conclusion: Linitis plastica is a carcinoma with a scirrhous stroma, involving the submucosal and muscular layers of the stomach even in the absence of mucosal alteration. In most cases, the primary cancer cells are signet-ring cells or scattered cells in the context of a poorly differentiated carcinoma. Diagnosis is challenging. Staging should be thorough, including diagnostic laparoscopy in all cases due to the high incidence of peritoneal involvement. The prognostic significance of linitis plastica is still controversial. Curative-intent surgery, when feasible, should be performed, with a multimodality treatment approach. Cancer-stroma interactions are important features of this disease, and represent attaining potential target for future therapies. Future pathologic assessments of gastric cancer should report the stromal reaction in order to allow better characterization of the tumor.
\end{abstract}

Keywords: Gastric cancer, Linitis plastica, Borrmann type IV, Scirrhous carcinoma, Diffuse, Signet ring

\section{Background}

Linitis plastica (LP) of the stomach is a long-known condition, with initial reports that date back to the sixteenth and seventeenth century [1]. It was defined as a distinct entity in 1859 by Dr. William Brinton, who described it as a benign disease with peculiar characteristics: the stomach was macroscopically thickened, with inconsistent evidence of mucosal ulceration; pathologically, it showed a prominent submucosal hypertrophy due to an increase in the connective tissue and prominent muscular hypertrophy.

\footnotetext{
* Correspondence: bbadgwell@mdanderson.org

${ }^{1}$ Department of Surgical Oncology, The University of Texas MD Anderson Cancer Center, Unit 1484, 1515 Holcombe Blvd., Houston, TX 77030, USA Full list of author information is available at the end of the article
}

The choice of the term "linitis" was due to the presence of irregular bands of filamentous tissue in the hypertrophic submucosa, resembling fibers of linen. Clinically, this disease was unavoidably fatal without treatment [2]. Early reports on the presence of cancerous cells in the setting of LP were notable for the difficulty in identifying malignancy. Malignant cells, when detected, were often described as few and scattered $[2,3]$. As a consequence, for many years, it was controversial if the condition was benign or malignant. Then, in 1953, Dr. Arthur Stout clarified the issue, proposing linitis plastica as a specific type of gastric carcinoma characterized by an excessive production of fibrous scarlike tissue, with areas in which only scattered cells were present. He also reported that the previous doubts on the 
malignant nature of LP were probably due to a failure in recognizing the presence of carcinoma cells by the past authors [4].

In the intervening years, multiple other classifications for gastric carcinoma have been established, reflecting the heterogeneity of this malignancy [5-8]. Each is based on different macroscopic and microscopic aspects of the tumor. LP had been associated with gastric carcinoma, but Stout's classification did not take hold, and LP was never included in any of the other staging systems. In the following years, the definition of LP was separated from the presence of fibrous tissue, becoming more generalized and being increasingly associated with diffuse carcinomas with infiltration of the gastric wall, resulting in the stomach having a stiffened appearance and a partial or complete lack of distensibility [9]; occasionally, the term has also been extended to include other conditions associated with thickening of the stomach wall without any fibrous component at all (i.e., lymphoma) $[10,11]$.

Recent reports of LP lack a clear and standardized codification. "Linitis plastica" is used interchangeably with "Borrmann type IV carcinoma," "scirrhous carcinoma," "signet-ring cell carcinoma," and "Lauren diffuse carcinoma" $[11,12]$. However, it is not clear if these terms correctly define this condition, as only some of the tumors in each of these categories have the features of LP.

Due to the lack of agreement on the clinical significance of LP and the difficulty in attributing this condition to the common classification systems, some authors have proposed to abandon this definition [13]. Others, nonetheless, still recognize in LP a specific type of gastric cancer with a distinct growth pattern and biological behavior, and advocate that the identification of such a subset of gastric cancer patients could be useful in risk stratification, in identifying a target for therapeutic management, and in guiding future research [14-18].

In recent years, the role of LP has come under discussion again with a focus on its prognostic significance. Many authors have associated this condition with diminished survival compared to non-linitis tumors, even proposing that this disease should be considered nonsurgical $[14,16,19]$. Conversely, there are reports noting a similar prognosis between LP and non-LP patients after stage-stratification or application of other adjustment methods [17]. Even in these studies that focused on investigating LP, the definition of LP is not uniform; hence, it is very difficult to interpret their results.

In this review, we assess the significance of LP in relation to the current classification systems, and propose working towards a univocal definition useful for clinical and research purposes. Furthermore, we summarize the diagnostic challenges of this condition, its prognostic aspects and its therapeutic implications, and discuss future research and clinical trial opportunities.

\section{Main text \\ Current classifications for gastric carcinoma and their relations to $\mathrm{LP}$}

Gastric cancer (GC) has several classifications related to its macroscopic and microscopic aspects. All are commonly used, but none of them has been accepted as the standard system. We hereby review the most common ones, addressing their overlap with LP.

Borrmann classification: first proposed by Borrmann in 1926 [5], this classification is most commonly used in Eastern countries $[8,12]$. It is based on the macroscopic endoscopical/endoluminal aspect of the tumor and is most useful as a preoperative assessment tool and a prognostic factor. Borrmann type IV tumors are described as diffuse and infiltrative ("tumor without diffuse ulceration or raised margin, the gastric wall is thickened and indurated, and the margin is unclear") [8] (Fig. 1). They represent $8-17 \%$ of GCs [20]. Clinicopathological characteristics of Borrmann IV tumors include an association with younger age and female gender, detection in an advanced stage, high incidence in the middle third or diffusely involving the entire stomach, predominance of Lauren diffuse-type and undifferentiated histology, deeper invasion of the gastric wall, a high rate of peritoneal and lymphatic involvement, low rate of liver metastases, and a high rate of recurrence after curative-intent surgery [20-22]. The natural history of Borrmann IV tumors has been investigated, and reports state that the

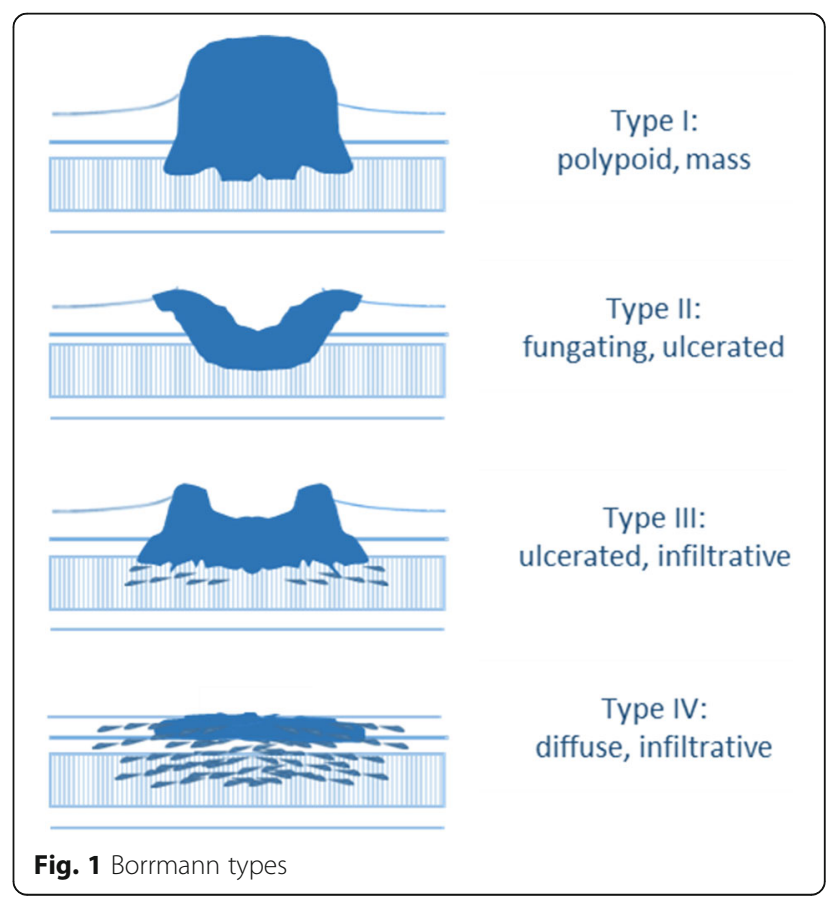


precursor of a Borrmann IV tumor is probably a Borrmann type 0-IIc lesion (a superficially depressed early GC) and not a Borrmann III lesion [11, 23-25]. Borrmann type III tumors, instead, represent 59-68\% [21, 22, 26] of GCs. They are characterized by both an infiltrative and ulcerative pattern [8] (Fig. 1), and their clinicopathological characteristic partially resemble those of Borrmann IV tumors [26]. Both Borrmann III and Borrmann IV tumors show an infiltrative pattern, and even Borrmann III tumors may show a consistent desmoplastic reaction [12]. At the same time, not every Borrmann IV tumor presents with the typical demoplastic characteristics of LP [11]. Therefore, LP is often improperly defined as a Borrmann IV tumor.

Cancer stromal volume classification: this microscopic classification is part of the Japanese classification [8]. It includes cancers with a medullary type (scanty stroma), a scirrhous type (abundant stroma), and an intermediate type. A similar system is utilized in the World Health Organization (WHO) classification (described below) [7], although tumor stroma is less commonly categorized by Western pathologists. In the Eastern setting, this classification is more commonly applied; however, there are few studies focusing on the clinicopathological aspects of tumors identified by the scirrhous classification system. Scirrhous cancers, in accordance with the original definitions of LP [2, 4], are strictly related to the LP phenotype, which presents in its classical form only when the submucosa is diffusely fibromatous [18]. In LP, the scirrhous component spreads primarily through the submucosa, with so much tropism that in some cases of LP the only endoscopic finding is an increase in the folds of the stomach [2,27]. Scirrhous carcinomas may be a Borrmann type III or IV $[12,28]$, and is reported to represent $5-43 \%$ of GCs [12, 16, 28, 29]. Clinicopathological characteristics of these tumors, in comparison with medullary carcinomas, include younger age, female prominence, more advanced stage, deeper invasion in the gastric wall, poor histologic differentiation, more peritoneal diffusion, less hematogenous diffusion, and more lymphatic invasion [16, 28].

Lauren classification: this microscopic classification divides gastric tumors into diffuse, intestinal, or mixed and indeterminate types. Diffuse adenocarcinomas are defined by their growth pattern as tumors infiltrating the stroma as discohesive tumor cells arranged singly and in small clusters. The intestinal type is defined by its cytoarchitecture, and characterized by cohesive cells which form gland-like structures. Mixed tumors have both an intestinal and diffuse component, while indeterminate types include most of the undifferentiated tumors $[6,7,30]$. Diffuse tumors account for $32-49 \%$ of GCs [31, 32]. There is a significant correlation between the diffuse histotype, the Borrmann III and IV types, and the scirrhous stromal category [31]. Diffuse histology has been frequently linked to LP [33], and it is also the typical pattern of familial hereditary diffuse GC, which in its advanced stages often presents as LP [7]. Clinicopathological characteristics of diffuse tumors include younger age, higher rate of incidence in the female gender, more advanced stage at presentation, more poorly differentiated tumors, more lymphovascular invasion, and more peritoneal dissemination [31, 34]. Unfortunately, despite its clinical success, the Lauren classification is broad, and may not valorize all the tumor features. In addition, mixed tumors have been reported to have a specific impact on prognosis, and to have possible subcategories themselves [35], and adding to the complexity of this classification is that mixed and indeterminate tumors have often been classified in either the intestinal or the diffuse category for reasons of simplicity.

WHO classification: The WHO classification is a descriptive system which defines five main types of gastric carcinoma: tubular, papillary, mucinous, poorly cohesive (including signet-ring cell carcinomas and other variants), and mixed adenocarcinomas. Lauren diffuse carcinomas most often have a poorly cohesive histotype. Signet-ring cell (SRC) carcinomas are defined as tumors composed of cells containing intracytoplasmic mucin and eccentrically placed nucleus, in a proportion $>50 \%$. They may form lace-like glands or a microtrabecular pattern in the mucosa, or extend to deeper layers with significant desmoplastic reaction. Irrespective of the category, SRCs may also be present in different tumors, as poorly cohesive variants, mucinous tumors (defined by extracellular mucin $>50 \%$ ), and mixed carcinomas (defined by a clonal mixture of both glandular and poorly cohesive aspects) [7]. Hereditary diffuse GC typically presents as a diffuse gastric carcinoma containing SRCs, and often with features of linitis plastica [7, 33].

The WHO classification also describes four stromal reactions (desmopasia/scirrhous reaction, lymphocytic infiltration, stromal eosinophilia, and a granulomatous response) and presents a grading (well, moderate, and poorly differentiated), which should be applied only to tubular and papillary variants of GC [7].

The WHO classification represent an exhaustive depiction of the various possible type of tumors by microscopic pattern, but has the limitation of being exclusively descriptive, not including the histogenesis of gastric adenocarcinoma, nor its biological behavior. This limitation is problematic when considering the WHO categories as prognostic factors, and the strict classification of SRC carcinoma (SRC $>50 \%$ ) does not account for the possible clinical significance of the presence of any SRCs, or for the possible significance of mucinous SRC tumors. Indeed, the mucinous category may contain SRCs in mucin pools, and mixed carcinomas are reported to have a more detrimental prognosis in regards 
to the presence of a SRC component [7]. In addition, it has been advocated that a subgroup of less differentiated mucinous tumors may have a pattern and prognosis similar to those of signet-ring cell tumors [36]. In general, however, SRC tumors account for $16-32 \%$ of all GCs [13, 37] and present similar clinicopathological characteristics to Borrmann IV, scirrhous, undifferentiated, and diffuse GC types [37]. Poorer prognosis has been reported by some authors [13] in comparison with other histotypes, while others have demonstrated equivalence of the prognosis in early stages [38] and in advanced stages after stage-adjustment [39].

Due to the variabilities in their diagnostic criteria and to the frequent coexistence of different histologic features in the same tumor, current microscopic classifications are not completely reliable. The comparison between preoperative biopsy and resection specimens shows disagreement in $25-35 \%$ of the cases with regards to Lauren classification and $16 \%$ with regards to the WHO system [30, 40]. Inter-observer disagreement on resected specimens ranges from 17 to $32 \%$ for the Lauren classification and from 21 to $32 \%$ for the WHO classification [30]. More confusion is induced by the fact that these classifications are used regionally (the application of the Lauren classification is not common in the East, while the Borrmann and stromal classifications are rarely used in the Western setting). For all these reasons, a manageable, reproducible, and universal classification system would be helpful.

Various novel classification systems, based on the genomic and epigenetic features of the tumors, are currently being developed for GC [41-44]. They have several theoretical advantages, being reproducible without room for subjective interpretation, abolishing categories as "indeterminate" or "mixed type" [33], and being directly linked to the biological behavior of the tumor. Furthermore, they could allow for the conception and development of targeted therapies [45]. Nonetheless, these methods are still expensive and not easily applicable $[43,45,46]$, and univocal classifications have yet to be developed. One current limit is represented by the low-frequency of certain molecular alterations, and the consequent need for largescale testing [47]. In regards to GC, the categories identified thus far are still heterogeneous, and there are still a vast number of potential targets for testing. None of the classifications proposed are specifically linked to scirrhous tumors or LP, but it seems highly probable that the LP phenotype may reside in the G-DIF (64\% concordance with Lauren diffuse tumors) [41], mesenchymal (high activity of epithelial-to-mesenchymal pathway, TGF- $\beta$ ) [44], GS (more Lauren diffuse tumors, defects in cell adhesion) [42], and MSS/EMT (Lauren diffuse, epithelial-tomesenchymal transition, less liver metastases) [43] subtypes defined by those classifications.

\section{Actual significance and features of linitis plastica}

Linitis plastica of the stomach is a distinct phenotype of gastric tumors. This term, as originally defined, includes both microscopic and macroscopic features.

\section{Histology}

The most characteristic feature of LP is the macroscopic thickening of the stomach wall, often diffusely involving the entire stomach, which has been described in detail since its early reports as an impressive increase in the submucosal connective tissue in the form of immature and mature stroma $[2,3]$ with hypertrophy of the muscle layer and subserosal thickening [48]. These characteristics strictly resemble those of scirrhous carcinoma, which, as mentioned above, is a particular form of GC in which cancer cells trigger a stromal reaction involving mature and immature fibrosis (which are characterized, respectively, by the presence of collagen I and III) $[49,50]$. The scirrhous reaction is almost always triggered by poorly cohesive neoplastic cells, often with signet-ring morphology. More rarely, cases of schirrous tumors accompanied by moderately differentiated adenocarcinomas have been reported [13, 15-19, 28].

Every cancer is composed by both the cancerous cells and their environment that consists of endothelial cells, inflammatory cells, and connective tissue (matrix and fibroblasts) [51, 52]. The importance of these interactions is increasingly being recognized, in contrast to previous research which has exclusively focused on cancer cells. Scirrhous tumors are characterized by a complex interaction between cancer cells and cancer-associated fibroblasts (CAFs), which may represent up to $90 \%$ of the tumor and appear to have a primary role in cancer progression. The origin of CAFs is under investigation; these cells seem to be heterogeneous, as they may be local fibroblasts, cells recruited from the bone marrow, or pericytes which undergo endothelial to mesenchymal transition [49, 52, 53]. Cell-stroma interactions have been associated to activated TGF-B, HGF (c-met ligand), FGF7, and other soluble factors [53, 54], yet they are complex and still have to be clarified.

Cells should not be analyzed without a parallel analysis of their environment, and in every case of properly defined scirrhous tumors, signet-ring or other poorly differentiated cells should be documented in conjunction with a scirrhous stroma (Fig. 2). Cases of scirrhous stromal reaction triggered by moderately differentiated intestinal tumors without the abovementioned cells have been documented as well, but seem to be extremely rare (Table 1 ).

\section{Secondary linitis plastica}

Insights on the biological behavior of scirrhous and LP tumors may also be gathered from the features of 


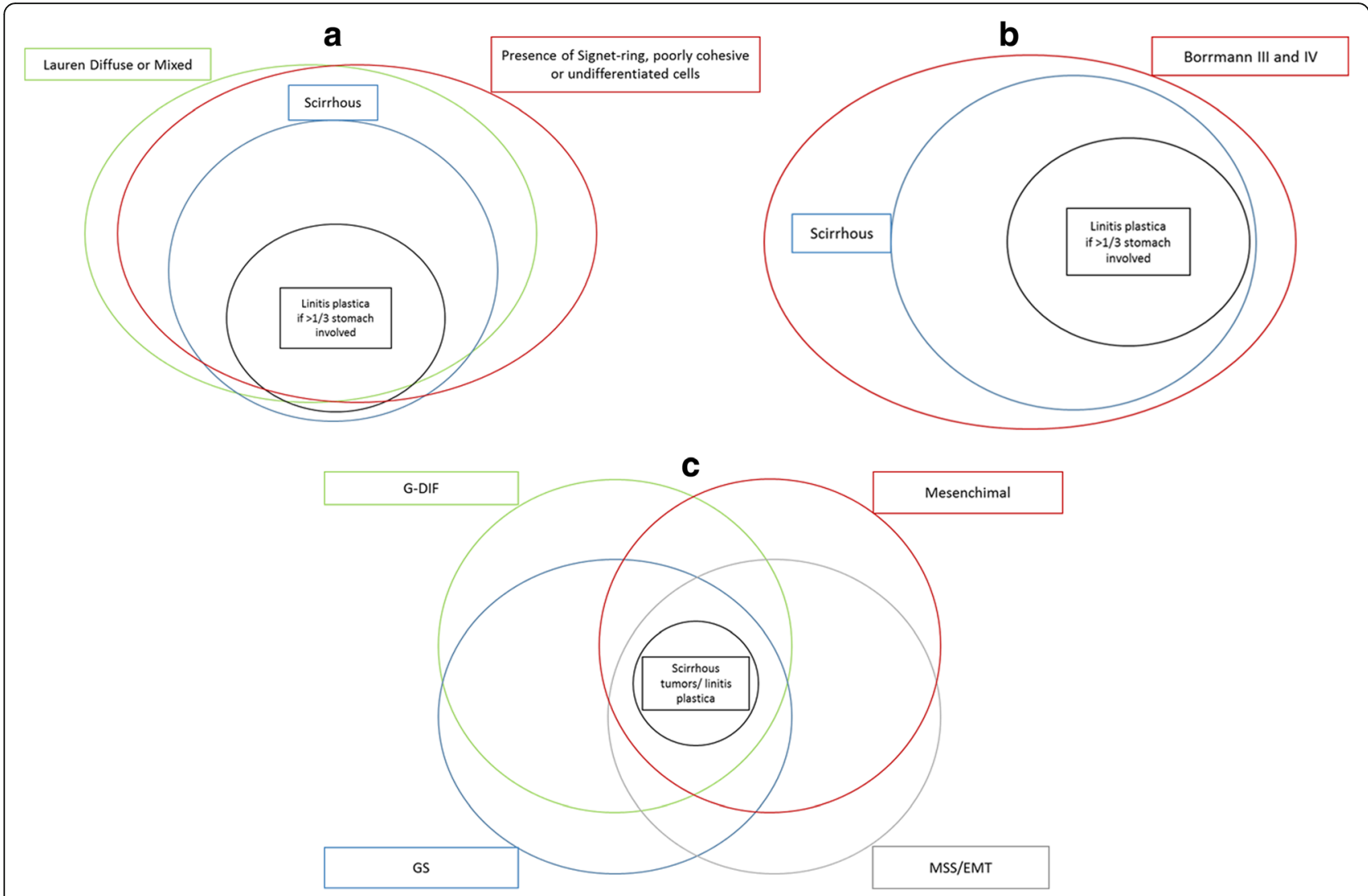

Fig. 2 Venn diagrams depicting the relations between the current classifications and linitis plastica. a Western setting. b Eastern setting. c Molecular classifications

Table 1 Characteristics of differing classifications of linitis plastica in the literature

\begin{tabular}{|c|c|c|c|c|c|}
\hline Author, year & Country & Diagnostic criteria & Age & Gender \% (M/F) & Histology \\
\hline Aranha, 1989 [76] & USA & Scirrhous + extension (unclear) & $62(42-80)$ & $42 / 58$ & $\begin{array}{l}100 \% \text { poorly differentiated } \\
\text { or anaplastic carcinoma, with } \\
\text { or without signet ring cells }\end{array}$ \\
\hline Hamy, 1999 [77] & France & Histology (infiltrating, SRCs) & $63.4 \pm 25.6$ & $59 / 41$ & $100 \%$ SRCs, $77 \%$ scirrhous \\
\hline Kodera, 2004 [70] & Japan & Histology (scirrhous) & $56.5 \pm 11.6$ & $53 / 47$ & Scirrhous \\
\hline Kodera, 2008 [75] & Japan & Barium meal or endoscopy & $59 \pm 11.5$ & $51 / 49$ & - \\
\hline Schauer, 2011 [15] & Germany & Locally advanced + SRCs & $57.7(28-83)$ & 1:1 & Diffuse \\
\hline Endo, 2012 [16] & Japan & Scirrhous + extension $>2 / 3$ & $69 \pm 7.7$ & $58 / 42$ & $\begin{array}{l}\text { 16\% SRC carcinoma, } 63 \% \text { poorly } \\
\text { differentiated, } 21 \% \text { moderately } \\
\text { differentiated }\end{array}$ \\
\hline Pedrazzani, 2012 [14] & Italy & $\begin{array}{l}\text { Lauren diffuse }+ \text { thickening of } \\
\text { the gastric wall }>1 / 3\end{array}$ & $68(29-89)$ & $56 / 44$ & Diffuse \\
\hline Jafferbhoy, 2013 [19] & UK & Nonspecified & $75(59-87)$ & - & - \\
\hline Blackham, 2016 [17] & USA & $\begin{array}{l}\text { Endoscopic assessment or intraoperative } \\
\text { assessment or histologic evaluation } \\
\text { (Borrnann, scirrhous) }\end{array}$ & $61.1 \pm 13$ & $47 / 53$ & $\begin{array}{l}98 \% \text { poorly differentiated } \\
2 \% \text { moderately differentiated }\end{array}$ \\
\hline Thompson, 2016 [78] & UK & Endoscopic or radiologic features (unclear) & $69.6 \pm 13.6$ & $50 / 50$ & Diffuse \\
\hline
\end{tabular}


secondary LP. Secondary LP features may be found in other hollow viscus or cystic organs, such as the bowel, bladder, and ovaries [27, 55]. Frequently, SRCs are detected in these types of secondary lesions $[18,56]$. At the same time, even secondary LP of the stomach has been described. The most commonly reported cases of secondary LP are those associated with metastatic invasive lobular carcinoma of the breast, which presents with identical radiologic [9] and nearly identical histologic characteristics to primary linitis plastica [57]. This condition may arise even 10 to 15 years after the initial diagnosis of breast cancer, rendering the past medical history essential to consider this diagnosis. Notably, lobular breast carcinoma is also a feature of hereditary diffuse GC [33], and it often contains scattered SRCs [57]. Scirrhous GCs seem to be more frequent in the female gender than other stromal types [16, 28], and have been reported to express ER in diverse studies [57]; these features could be imputed to gastric CAFs being a common soil for tumors in which hormones have a specific role. On the other hand, some authors have suggested that, if a high level of suspicion was kept and routine testing for biomarkers of breast carcinoma applied, a secondary breast origin for LP would be detected in more cases $[57,58]$.

\section{Mucosal involvement}

In regards to the quality of the mucosal involvement, two different subtypes of linitis plastica have been described (Fig. 3). In the first type, giant-fold or waffle-like, the mucosa demonstrates a characteristic morphological change consisting of an enhancement of the design of the folds, which remain flexible but appear prominent and crossing one another. This effect may be due to the relatively normal state of the mucosa in comparison to the involvement and contraction of the submucosal and muscular layers $[2,11]$. The pattern of waffle-like LP has been extensively described in several Japanese studies, and in case reports of patients refusing surgery and subsequently being followed for years [11, 23-25]. The first lesion generally originates from the proximal or middle stomach, near the great curve, as a type IIc (flat depressed) early GC. This condition may remain stable for 2-5 years (slow-phase), until the lesion progresses to advanced GC and ulcerates reaching the submucosal layer. At this point, the ulcerative lesion can persist or heal, while the submucosal involvement, once a scirrhous reaction is initiated, enters a fast-phase, involving the entire stomach (LP) in about 1 year [23-25].

In the second type, the flat type, submucosal involvement is paralleled by mucosal thickening or atrophy [11]. This type most commonly originates from the antrum, near the lesser curvature, and then extends to involve the antrum circumferentially. Flat type LP development has not been extensively studied. The difference between the characteristic mucosal pattern in waffle-like LP and the mucosal flattening and induration in flat type LP may due to diffusion of the neoplasm in a more superficial plane (involving the lamina propria, the muscolaris propria, or the mucosa itself) in flat type. The tumor is thought to originate near the pylorus, involve the antrum circumferentially, and extend to the

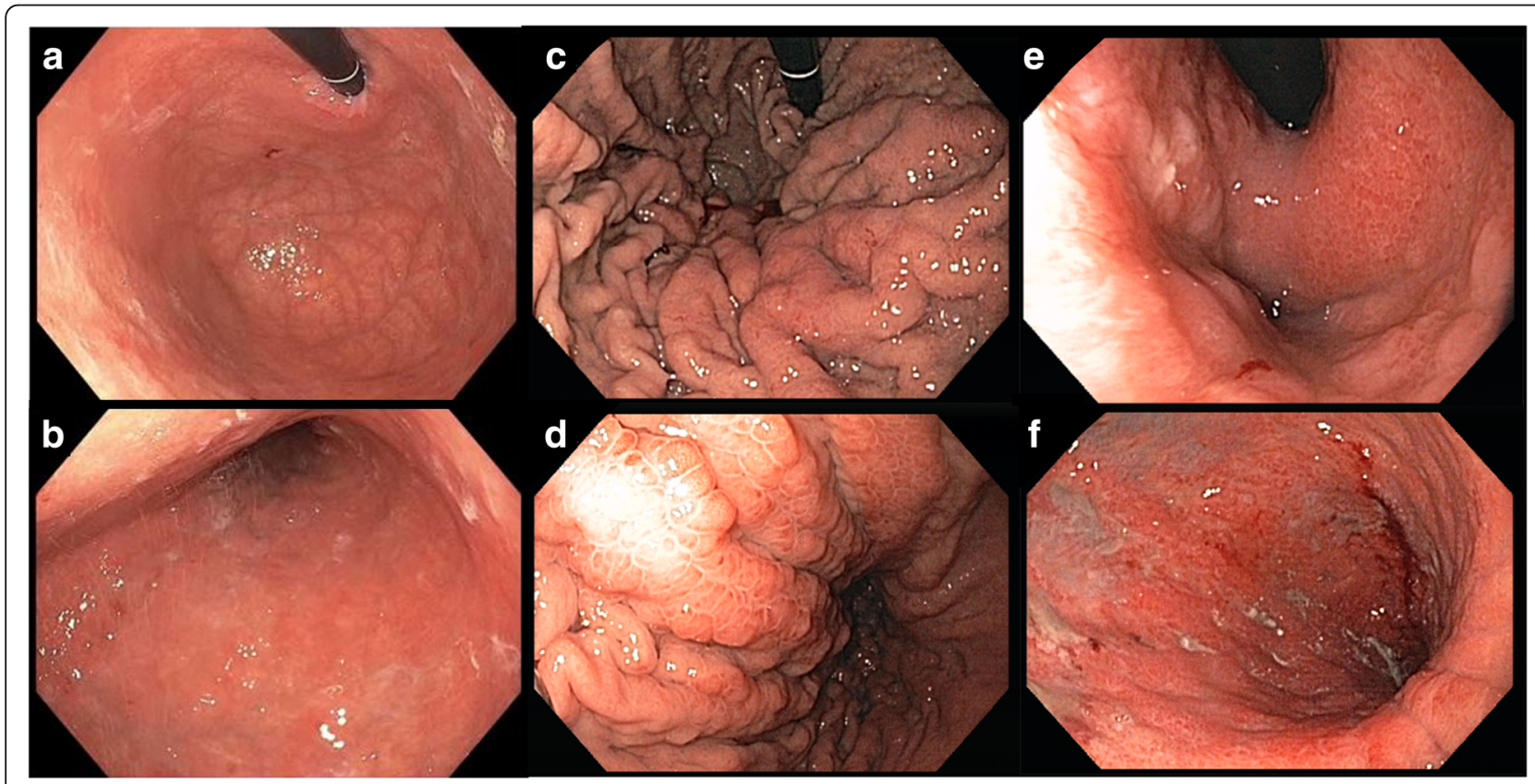

Fig. $\mathbf{3}$ Endoscopic aspect of two different types of linitis plastica: the waffle-like $(\mathbf{c}, \mathbf{d})$ and the flat type $(\mathbf{e}, \mathbf{f}) . \mathbf{a}, \mathbf{b}$ The aspect of a normal stomach 
entire stomach $[9,19,27]$. The flat type is commonly believed to be the most common in Western settings [11]. However, even if the original description by Brinton, most of the LP cases were identified as originating from the distal stomach, with hypertrophic mucosal folds [2], and a mixture of both subtypes [11]. In 1990, a US study demonstrated that up to $88 \%$ patients with scirrhous tumors present with the radiological features of thickened gastric folds. Moreover, in this study, 38\% presented with mainly proximal involvement and 35\% with mainly distal involvement [9]. Conversely, a 2004 Korean survey has reported a $22 \%$ rate of primarily proximal and a $59 \%$ rate of primarily distal involvement [12]. Therefore, the distinction between these two types is not clear-cut.

\section{Extension and macroscopic features}

LP does not always present as complete involvement of the stomach. It may appear in plaques which gives the appearance of a segmental lack of distensibility [9, 12]. Localized and diffuse forms of linitis were found in the early reports of this condition [2, 3], and recent evidence seem to have confirmed that the submucosal and muscular involvement by the scirrhous reaction is progressive. Indeed, Endo et al. [16] have been investigating localized schirrous tumors versus extended forms of LP, identifying similar gender rates, histology, and lymphatic invasion between these tumors, and a progression from younger towards older age and from less towards more advanced stage between the localized and diffuse forms. In relation to the Japanese studies on the growth pattern of scirrhous tumors [24, 25], many have proposed that the localized form may correspond to a relatively stable scirrhous disease, which is followed by a rapid phase of growth in which the desmoplastic reaction rapidly involves most of the stomach [16].

There are also multiple proposed definitions for LP based on extent of gastric involvement (Table 1). Nakamura et al. [25] defined typical LP as involvement of more than $1 / 4$ of the stomach; Pedrazzani et al. [14] proposed a cut-off of 1/3, and Endo et al. [16] a limit of 2/3; each of these classifications has only been applied once, and neither of them specify if the involvement had been pre- or postoperative or if it is intended for both the anterior and the posterior aspect of the stomach.

\section{Definition: postoperative or preoperative?}

LP is, by the original definition, a scirrhous tumor that spreads through the submucosal and muscular layers of the stomach, with thickening of its wall and loss of distensibility. The presence of poorly differentiated, poorly cohesive, or SRCs is often involved (Fig. 4).

However, the original definition is based on autopsies and surgical specimens, and it should be noted that it may be difficult to obtain a reliable biopsy documenting both the predominance of the stroma and the cancerous cells in the preoperative setting. Moreover, many of these patients, affected by advanced disease, would not undergo gastrectomy; therefore, analysis on postoperative surgical specimens would not always be possible. In addition, the increasingly common practice of administering preoperative therapy in the form of systemic chemotherapy or radiotherapy may hamper the identification of the typical stromal reaction of LP, as fibrosis is often a consequence of preoperative therapy [59].

Therefore, on the one hand, the identification of the specific morphologic characteristics of a tumor with a special biological behavior remains extremely important to improve understanding of the disease (see next paragraph), on the other there is the need for a simpler definition (univocal as well), which could be used in the clinical practice to aid oncologists and surgeons to stratify the prognosis of gastric cancer patients and define the therapeutic strategy even preoperatively. Thus, the most useful definition would probably be a preoperative one. To be simple and easily obtainable, it should also be macroscopic, with a cut-off extension over which the

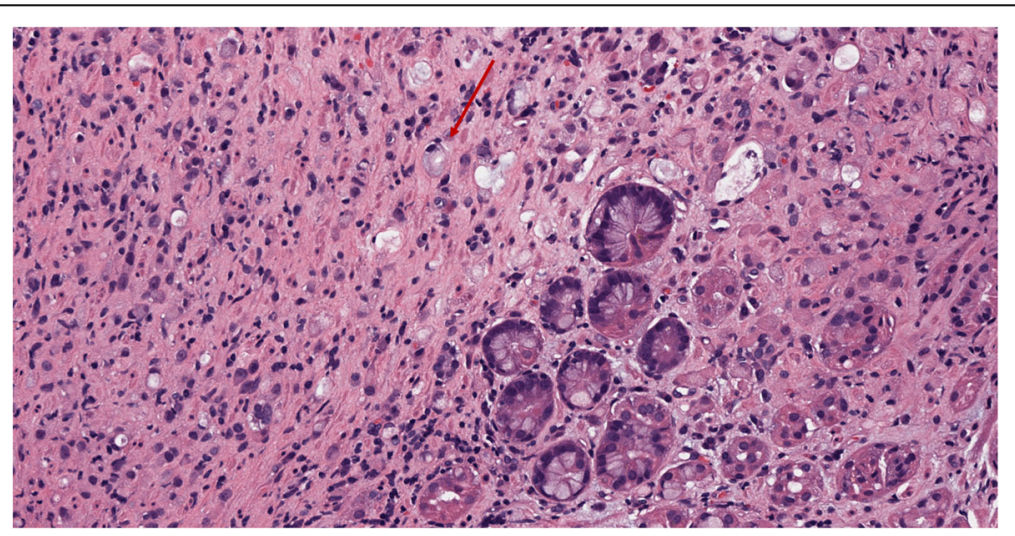

Fig. 4 Histological features of scirrhous tumors. Note the prominence of the stroma (especially on the left). Red arrow: a scattered signet-ring cell 
LP phenotype is clearly identifiable. This would guarantee a uniform identification of the condition and represent a good surrogate for the tumor phenotype. In our opinion, this definition could include thickening of the gastric wall, with lack of distensibility, which involves more than $1 / 3$ of the gastric surface, both as a circumferential involvement of more than one area, or a semicircular involvement of more than two areas (Fig. 5).

\section{Perspectives}

What could be the role of distinguishing LP in the era of genomics? The concept of linitis plastica is unique in that it links diverse aspects of specific subtypes of tumors (macroscopic, microscopic, and environmental). Maintaining the LP definition and linking it to the stromal reaction could be useful for future studies and for genomic investigations, as patients with typical LP may be a relatively homogeneous subset of patients with a distinct tumor biologic behavior, in which specific genetic and epigenetic changes may be easier to detect than in the entire class of G-DIF and GS tumors. In particular, interesting expression changes are those happening in the cancer cells when the tumor activates the scirrhous response and the epithelial-to mesenchymal transition [43]. For years, oncological researchers have been focusing on cancer cell analysis, while more recently the attention is shifting towards analysis of the cellenvironment relation [53], of which scirrhous tumors and linitis plastica seem to be a perfect example. In this regard, direct molecular profiling of LP CAFs would also be of great interest.

\section{Linitis plastica: diagnostic challenges}

Typical symptoms of LP are dyspepsia, nausea, vomiting, and anorexia. Unfortunately, those symptoms are not reliable for establishing a timely diagnosis, as they usually present insidiously, and manifest only in an advanced stage. Available diagnostic instruments for this condition include endoscopy, endoscopic ultrasound (EUS), upper gastrointestinal contrast studies (UGI), computed tomography (CT) and 18-fludeoxyglucose (18-FDG) positron emission tomography (PET) scans, and magnetic resonance imaging (MRI) (Fig. 6).

Endoscopy is considered the gold standard for the diagnosis of GC. However, the peculiar spread pattern of LP tumors involves primarily the submucosa and muscularis propria of the stomach, while mucosal involvement is inconstant and may present as nonspecific gastritis or normal mucosa in up to $30 \%$ of cases [11]. The flat type could be confused with atrophic gastritis and suspected by endoscopy sometimes only due to the lack of distension of the stomach wall. Waffle-like appearance of the mucosa is more characteristic, even if biopsies have the same low diagnostic yield. Due to their poorly cohesive nature, cancer cells are often scattered between the tumor stroma [12, 56] (Fig. 4) or even absent in some sections [27]. Indeed, studies show high rates of non-diagnostic biopsies (30-36\%) [9, 60]. Sometimes, the delay in the histologic diagnosis may represent

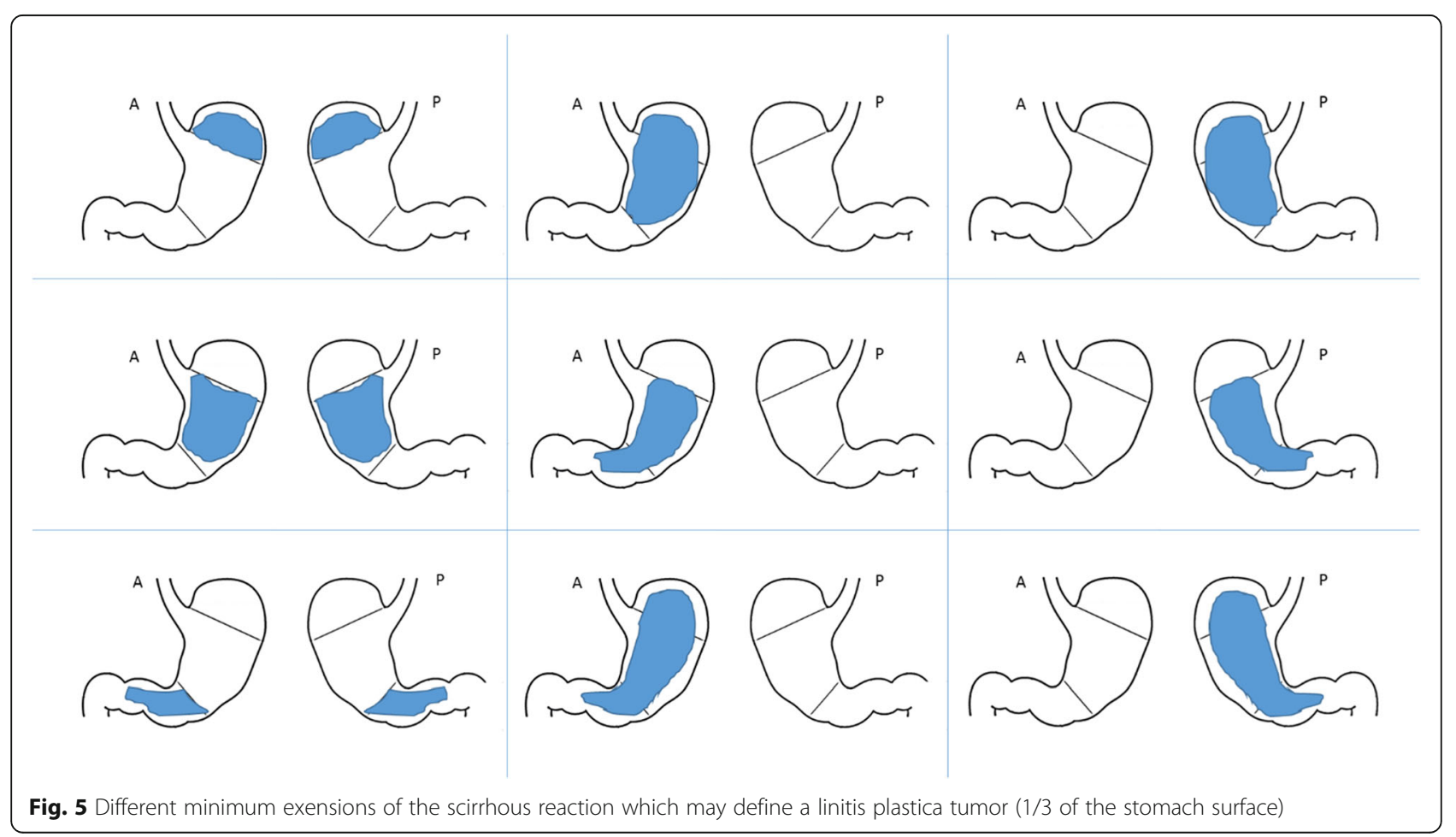




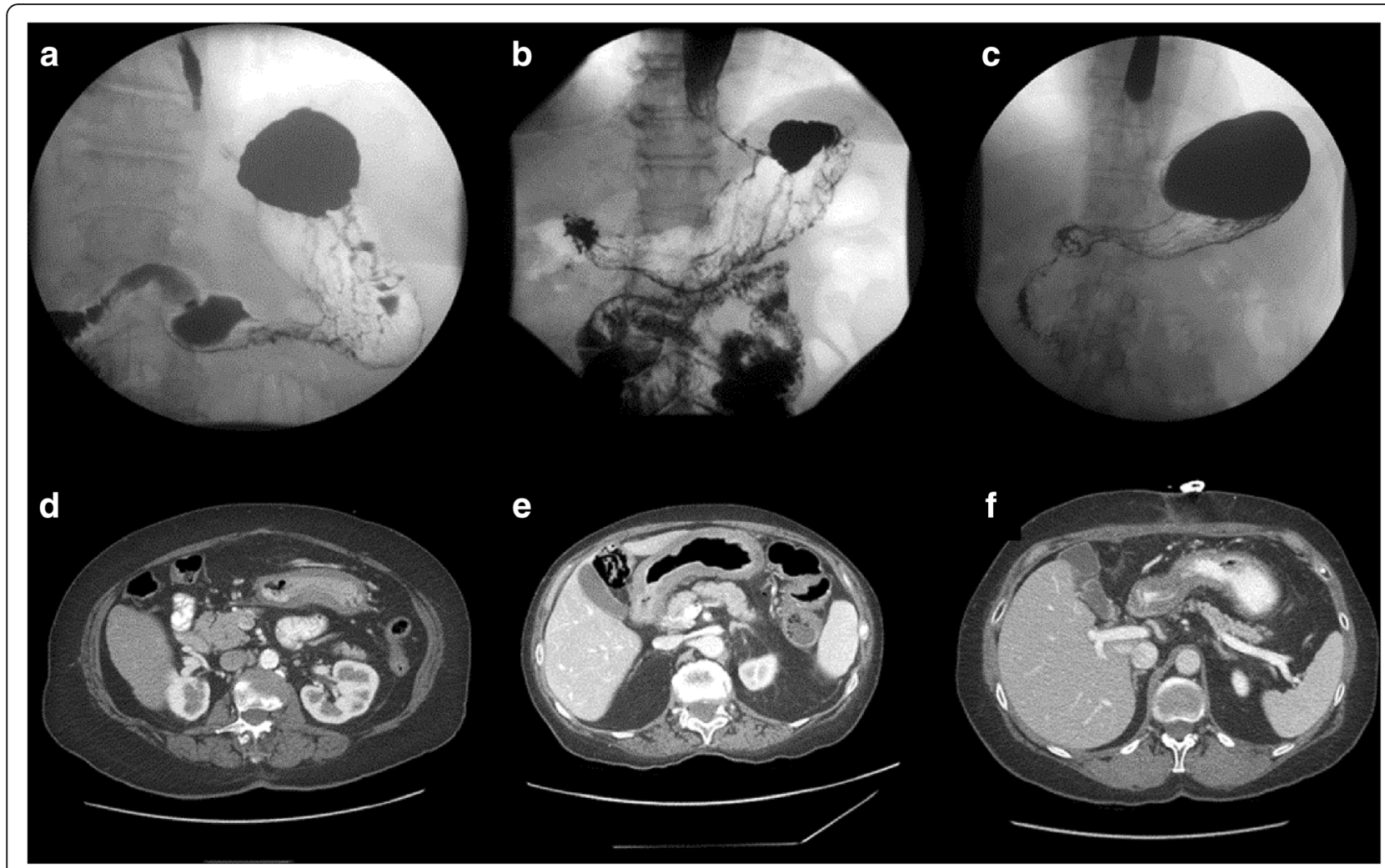

Fig. 6 Upper gastrointestinal imaging $(\mathbf{a}-\mathbf{c})$ and computed tomography $(\mathbf{d}-\mathbf{f})$ diagnostic features of linitis plastica in three different patients (patient 1: a, d; patient 2: b, e; patient 3: c, f)

a serious challenge, especially when the clinical and instrumental suspicion of LP is strong, as several different diagnoses are possible in the presence of hypertrophic mucosal folds and/or scarce distensibility of the stomach (gastric lymphoma, Ménétrier disease, granulomatous diseases and metastasis) and not all of them are surgical [9, 11, 27]. Gastrectomy is a major procedure with considerable morbidity and mortality, and many clinicians would not perform resection until cancer has been proven by biopsy.

Several endoscopic strategies to better diagnose this disease have been proposed. EUS features include submucosal and muscular thickening, and EUS fine-needle aspiration allows reaching of the submucosal layer [11, 18]. Even with this strategy, however, negative biopsies have been reported [61]. For this reason, EUS is also not considered the gold standard in diagnosis of LP. Endoscopic mucosal resection, due to the deep involvement of the stomach wall and the greater submucosal involvement, may not be ideal [62]; instead, other authors have been proposing a mucosal flap with submucosal endoscopic resection [61]. In addition, after the introduction of new-generation endoscopic techniques (endocytoscopy and endomicroscopy), there have been various reports on the detection of SRCs in vivo $[63,64]$.
Barium studies can be a useful diagnostic instrument, as they could document the thickening of the mucosal folds, and assess in real time the segmental or complete lack of distensibility of the gastric wall. In 2004, Park et al. reported UGI to be more reliable than endoscopy in detecting both the Borrmann type and the location of the primary tumor when evaluating scirrhous carcinomas [12]. UGI has been progressively discarded as a diagnostic technique for gastric cancer diagnosis and staging; nevertheless, given the low sensibility of conventional endoscopy, it remains of valuable support in evaluating this condition.

CT allows for comprehensive staging of the tumor, and could give rise to reasonable suspicion when identifying a stomach with thickened walls, which presents with complete flattening of the mucosal folds or thickened folds even after distension [55, 65] (Fig. 6). Two studies focusing on the diagnostic yield of CT have described a specific enhancement pattern in LP patients $[55,65]$. 18FDG PET, by the contrary, may have scarce diagnostic significance, as poorly differentiated, diffuse, mucinous, and SRC carcinomas have all been reported to be low in 18-FDG uptake [66].

MRI has been recently proposed as an alternative to $\mathrm{CT}$, due to its advantages in characterizing tissue nature 
and obtaining soft tissue contrast [67], but the topic is still controversial [68]. One recent study identified a significant association between the apparent diffusion coefficient obtained with diffusion weighted imaging during MRI and different histological types, degrees of differentiation, and Lauren classification [69].

Suspicion of linitis plastica should prompt consideration for laparoscopy in staging. In consideration of the well-known peritoneal tropism of the disease, a diagnostic laparoscopy with peritoneal washings should be mandatory to complete the staging, if technically possible and not limited by previous surgery. Indeed, previous studies had reported positive cytology and macroscopic carcinomatosis in $49-64 \%$ of patients with LP undergoing diagnostic laparoscopy [15, 70, 71]. Moreover, laparoscopic biopsies of the gastric wall could be diriment in selected cases (i.e., when a histologic diagnosis is not obtainable even after repeated endoscopies).

A gold-standard diagnostic instrument for LP has yet to be defined. Proposals for diagnostic algorithms have been reported [11]. However, in the absence of clear definition for LP, the development of a diagnostic strategy is difficult. Moreover, macroscopic and microscopic assessments of the stomach are both required to identify the condition. If the suspicion is strong, even in the absence of a positive biopsy, the possible diagnoses should be discussed with the patient, and a diagnostic laparoscopy proposed to avoid deleterious diagnostic delays.

Future diagnostic advancements may be obtained by the use of blood-based biomarkers. In 2000, Ichikawa et al. proposed a high level of trypsinogen as a simple and specific marker to diagnose linitis plastica, but this marker has not been further tested or introduced in clinical practice [72]. "Liquid biopsy" of circulating tumor cells, cDNA, or miRNA may represent a future perspective $[73,74]$, especially as genomic and epigenetic characteristics of GC are better understood.

\section{Linitis plastica: impact on prognosis}

Diverse studies have evaluated the prognostic significance of LP throughout the years (Table 2) [14-17, 19, 70, 75-78]. The absence of assessment of the stromal component and the use of non-standardized definitions (based on heterogeneous microscopic and macroscopic criteria) represent a notable limit of these studies. Nonetheless, some common prognostic features have been detected.

In general, scirrhous tumors present a unique biologic behavior, which is believed to be more aggressive than that of other gastric tumors, with a specific tropism for lymphnode and peritoneal involvement [16]. Prognosis of LP patients seem also to be dismal, with frequent presentation with advanced stage disease, poorer disease-free survival, higher rate of peritoneal recurrence, low rate of hepatic metastases, and a median overall survival rate ranging from 5.7 to 13.8 months [14-17, 19, 70, 75-78]. Some authors have also reported a high non-curative resection rate $[14,15,17,70,75,78]$, with LP disease often detected in the resection margins $[17,75]$. Nevertheless, some of the studies report an equivalent prognosis for LP and non-LP patients when results were adjusted by stage [17], or detected a prognostic advantage for LP patients undergoing R0 resection [14, 15, 17, 75].

Most studies have been conducted on small, nonstandardized Western populations [14, 15, 17]. Studies on LP often present mixed populations of curativeintent versus palliative-intent patients, and apply multivariate analysis as adjustment method on small sample sizes. In those analyses, possible confounders and effect modifiers are not always considered, and it is still not clear if LP may represent a real independent prognostic factor or a confounder. As randomization is not easily feasible in this setting, an interesting approach may be the use of propensity-score matching [79] to balance the characteristics between LP and non-LP patients. Waiting for new evidences, the debate is still open. Meanwhile, patients should not be denied treatment on the basis of a preoperative diagnosis of LP when curative-aim surgery is possible.

\section{Linitis plastica: implications for therapy}

As soon as the possibility of a curative treatment for a patient with LP is assessed, other questions arise in regards to the therapeutic management.

For years, ample resection margins $(>5 \mathrm{~cm})$ have been advocated to avoid R1 resection in GC patients, and they are considered the current standard for patients with Borrmann III and IV tumors, in accordance with the Japanese Guidelines [80]. This topic, however, is extremely controversial. Indeed, a discrete number of studies seem to have disproved the value of wide resection margins, as long as a R0 resection is obtained, while other studies have even been questioning the role of R0 resection in advanced stages [81, 82]. However, studies focusing on diffuse, SRC, and especially on scirrhous tumors are lacking. Thus, caution is needed when performing limited resections in these subgroups. Given its high accuracy [17, 81], a frozen tissue biopsy should be routinely performed. If a frozen tissue biopsy is not available, a margin of $5 \mathrm{~cm}$ currently remains the gold standard. It should also be considered that in scirrhous gastric cancers and LP phenotypes a frozen tissue could be less reliable due to the lack of tumor cellularity.

Recently, much attention has been given to the use of preoperative hyperthermic intraperitoneal chemotherapy (HIPEC) in GC, both for the prevention of peritoneal disease and for its treatment, and a few randomized investigations are ongoing [83]. Given the strong peritoneal 


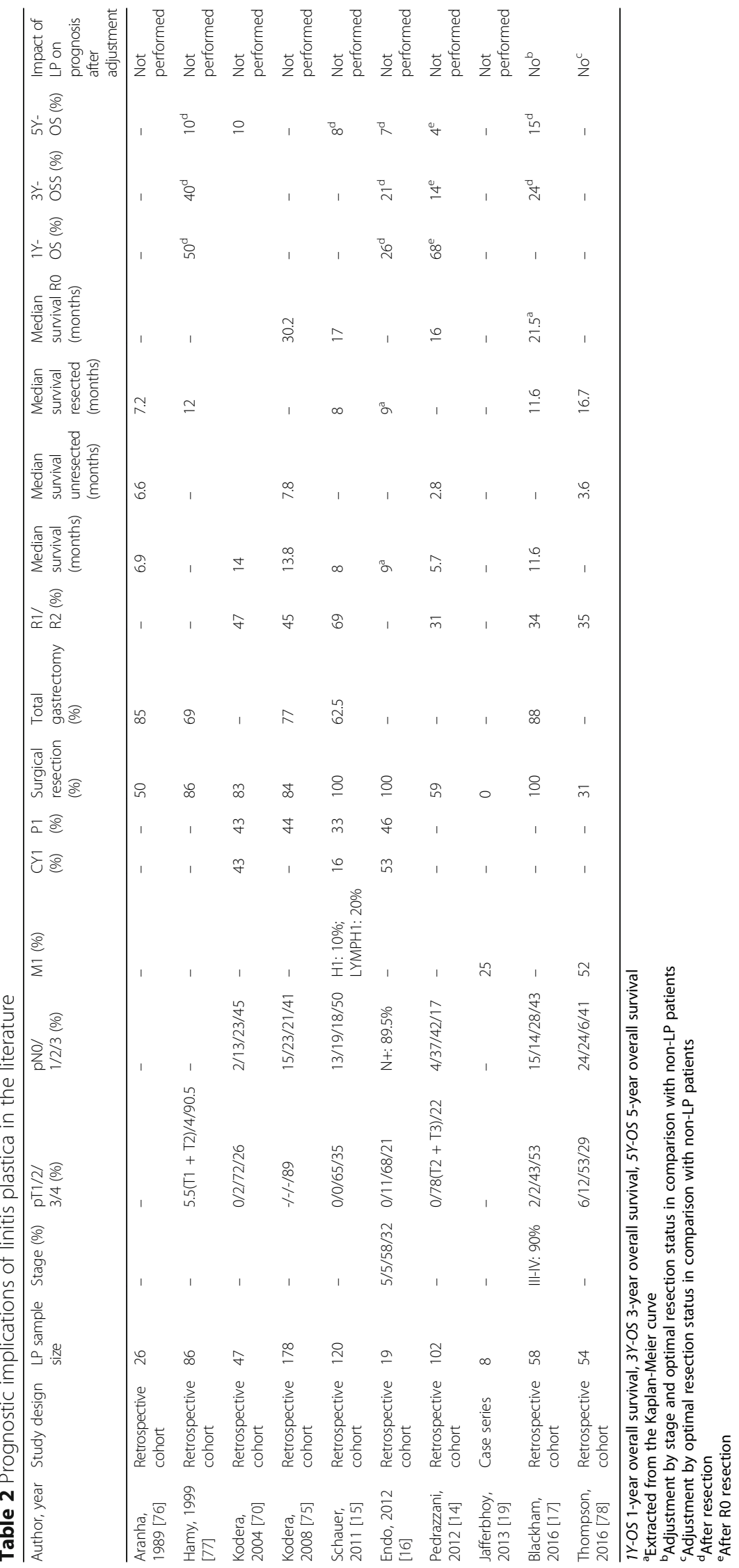


tropism of scirrhous and LP tumors, in the near-future, HIPEC could come to the foreground for the routine management of this subgroup of patients.

Neoadjuvant therapy has many theoretical advantages. Among them are the higher rate of treatment compliance in comparison to postoperative therapy, and the possibility of downstaging or downsizing the tumor [84]. As LP tumors often present in an advanced stage, neoadjuvant therapy may be of particular value in improving local control and increasing the rate of potentially curative gastrectomies.

Nevertheless, concerns remain when applying conventional therapeutic agents. The use of radiotherapy as an adjuvant treatment was significantly less effective in diffuse tumors in both the ARTIST trial and the 10-year update of the INT-0116 trial $[85,86]$. In vitro testing on the G-DIF gene-expressing subtype demonstrated reduced sensitivity to 5-fluorouracyl and oxaliplatin in comparison to cisplatin [41]. In a 2004 survey, the use of cisplatin as intraperitoneal preoperative lavage in patients with $\mathrm{CY}+$ schirrous tumors gave no survival benefit in comparison to non-operative management [29]. HER-2 activating mutations are rare between the GS, the MSS/EMT, and the mesenchymal metabolic subtypes [42-44], so Trastuzumab is rarely an option. Finally, in a retrospective French study, patients with SRC tumors have been reported to show scarce response to standard perioperative chemotherapeutic regimens and poor survival [87], due to possible progression of the disease during neoadjuvant therapy, and a phase III randomized clinical trial is currently ongoing to assess the role of perioperative versus adjuvant chemotherapy in this subset [88].

At this point, further studies should be conducted to assess chemo- and radiosensitivity to standard regimens in schirrous tumors and LP, and to evaluate if, in this subset of patients, neoadjuvant treatments are more appropriate than upfront gastrectomy plus adjuvant therapy. Similarly, advancements are needed in identifying the efficacy of different HIPEC drugs.

Currently, targeted therapy is considered only for certain GC subtypes [45], and almost all the chemotherapeutic regimens are directed solely against the cancerous cells. Scirrhous tumors, though, have several distinct features that may be strictly related to their aggressive biological behavior. Their desmoplastic stroma may represent both an enhancer of tumor cell growth and invasiveness [53] and a shield against the host's immune response and against standard chemotherapy [51]. On the one hand, this consideration may be a topic in favor of upfront gastrectomy (with the strategy of removing the "shield," then treating minimal residual disease); on the other, it should prompt the development of agents targeted against the cancer-stroma interaction factors or against the stromal cells. This strategy may represent a real game-change in the context of a multimodal therapeutic management, especially for patients which are non-responders to conventional therapy. In this regard, interesting preliminary effects have been observed with Tranilast (a mast-cell and fibroblast inhibitor) [89], and TGF-B and FGF7 receptor inhibitors $[90,91]$ in association with standard chemotherapy. Further advancements in the understanding of tumor-stroma interactions are expected.

\section{Conclusions}

Primary linitis plastica of the stomach is a diffuse-type carcinoma with a scirrhous stroma, which invades the submucosa involving more than $1 / 3$ of the stomach surface. Currently, appropriate management strategies include an accurate diagnostic multi-instrumental assessment and diagnostic laparoscopy in all cases. Curative-aim surgery, when feasible, should be performed. For these patients, the role of neoadjuvant therapy has to be assessed, and the impact of standard chemo and radiotherapy protocols should be further analyzed. Pre- or postoperative HIPEC may represent an alternate strategy, especially given the high rates of peritoneal spread of this tumor. Further advancements are needed in regards to the development of targeted therapies, which will address both cancer cells and their stroma. Future studies on scirrhous tumors and LP should be based on a standardized definition such as the one proposed. Moreover, Western pathologist should introduce in routine examinations the assessment of the stromal reaction, to allow for better patients' stratification and on par comparison with the Eastern setting.

\section{Abbreviations \\ 18-FDG: 18-Fludeoxyglucose; CAFs: Cancer-associated fibroblasts; CT: Computed tomography; EUS: Endoscopic ultrasound; GC: Gastric cancer; HIPEC: Hypertermic intraperitoneal chemotherapy; LP: Linitis plastica; MRI: Magnetic resonance imaging; PET: Positron emission tomography; SRC: Signet-ring cell; UGI: Upper gastrointestinal series; WHO: World Health Organization}

\section{Acknowledgements}

Not applicable.

\section{Funding \\ None.}

Availability of data and materials

Not applicable.

\section{Authors' contributions}

$\mathrm{AA}$ and $\mathrm{BB}$ conceived the study and participated in its design. AA drafted the manuscript. JSE and BB helped in revising the paper critically for important intellectual content. All authors read and approved the final manuscript.

Ethics approval and consent to participate Not applicable.

Consent for publication Not applicable. 


\section{Competing interests}

The authors declare that they have no competing interests.

\section{Publisher's Note}

Springer Nature remains neutral with regard to jurisdictional claims in published maps and institutional affiliations.

\section{Author details}

'Department of Surgical Oncology, The University of Texas MD Anderson Cancer Center, Unit 1484, 1515 Holcombe Blvd., Houston, TX 77030, USA 2Department of Pathology, The University of Texas MD Anderson Cancer Center, Houston, TX, USA.

\section{Received: 27 December 2016 Accepted: 22 June 2017} Published online: 05 July 2017

\section{References}

1. Lyle HH. VIII. Linitis plastica (cirrhosis of stomach): with a report of a case cured by gastro-jejunostomy. Ann Surg. 1911;54:625-68.

2. Brinton $\mathbf{W}$. The diseases of the stomach, with an introduction on its anatomy and physiology; being lectures delivered at St. Thomas's hospital. London: J. Churchill; 1859.

3. Armstrong GE. Linitis plastica. Can Med Assoc J. 1914;4:770-5.

4. Stout AP. Tumors of the stomach. Washington: Armed Forces Institute of Pathology; 1953.

5. Borrmann R. Geschwülste des Magens und Duodenums. Verdauungsschlauch. Berlin: Springer; 1926. p. 812-1054.

6. Lauren P. The two histological main types of gastric carcinoma: diffuse and so-called intestinal-type carcinoma. An attempt at a histo-clinical classification. Acta Pathol Microbiol Scand. 1965;64:31-49.

7. Bosman FT, World Health Organization. International Agency for Research on Cancer. WHO classification of tumours of the digestive system. 4th ed. Lyon: International Agency for Research on Cancer; 2010.

8. Association JGC. Japanese classification of gastric carcinoma: 3rd English edition. Gastric Cancer. 2011;14:101-12.

9. Levine MS, Kong V, Rubesin SE, Laufer I, Herlinger H. Scirrhous carcinoma of the stomach: radiologic and endoscopic diagnosis. Radiology. 1990;175:151-

10. Levine MS, Pantongrag-Brown L, Aguilera NS, Buck JL, Buetow PC. NonHodgkin lymphoma of the stomach: a cause of linitis plastica. Radiology. 1996;201:375-8.

11. Jung K, Park MI, Kim SE, Park SJ. Borrmann type 4 advanced gastric cancer: focus on the development of scirrhous gastric cancer. Clin Endosc. 2016;49: 336-45.

12. Park MS, Ha HK, Choi BS, Kim KW, Myung SJ, Kim AY, et al. Scirrhous gastric carcinoma: endoscopy versus upper gastrointestinal radiography. Radiology. 2004;231:421-6.

13. Piessen $G$, Messager $M$, Leteurtre $E$, Jean-Pierre $T$, Mariette $C$. Signet ring cell histology is an independent predictor of poor prognosis in gastric adenocarcinoma regardless of tumoral clinical presentation. Ann Surg. 2009; 250:878-87.

14. Pedrazzani C, Marrelli D, Pacelli F, Di Cosmo M, Mura G, Bettarini F, et al. Gastric linitis plastica: which role for surgical resection? Gastric Cancer. 2012; 15:56-60.

15. Schauer M, Peiper M, Theisen J, Knoefel W. Prognostic factors in patients with diffuse type gastric cancer (linitis plastica) after operative treatment. Eur J Med Res. 2011:16:29-33.

16. Endo K, Sakurai M, Kusumoto E, Uehara H, Yamaguchi S, Tsutsumi N, et al. Biological significance of localized Type IV scirrhous gastric cancer. Oncol Lett. 2012;3:94-9.

17. Blackham AU, Swords DS, Levine EA, Fino NF, Squires MH, Poultsides G, et al. Is linitis plastica a contraindication for surgical resection: a multiinstitution study of the U.S. Gastric Cancer Collaborative. Ann Surg Oncol. 2016:23:1203-11

18. Mastoraki A, Papanikolaou IS, Sakorafas G, Safioleas M. Facing the challenge of managing linitis plastica—review of the literature. Hepatogastroenterology. 2009;56:1773-8.

19. Jafferbhoy S, Shiwani H, Rustum Q. Managing gastric linitis plastica: keep the scalpel sheathed. Sultan Qaboos Univ Med J. 2013;13:451-3.
20. Luo Y, Gao P, Song Y, Sun J, Huang X, Zhao J, et al. Clinicopathologic characteristics and prognosis of Borrmann type IV gastric cancer: a metaanalysis. World J Surg Oncol. 2016;14:49.

21. An JY, Kang TH, Choi MG, Noh JH, Sohn TS, Kim S. Borrmann type IV: an independent prognostic factor for survival in gastric cancer. J Gastrointest Surg. 2008;12:1364-9.

22. Huang JY, Wang ZN, Lu CY, Miao ZF, Zhu Z, Song YX, et al. Borrmann type IV gastric cancer should be classified as pT4b disease. J Surg Res. 2016;203:258-67.

23. Itoh H, Nakata H, Nishioka S, Aikawa K, Yokoya Y, Nakayama T, et al. Gastric cancer retrospectively investigated for 9 years and 6 months: a case of linitis plastica. Dig Endosc. 2000;12:191-5.

24. Oguro Y. Endoscopic diagnosis of scirrhous gastric carcinoma. Gan To Kagaku Ryoho. 1994;21:2384-91.

25. Nakamura K, Kato Y, Misono T, Sugano H, Sugiyama N, Baba Y, et al. Growing process to carcinoma of linitis plastica type of the stomach from cancer-development. Stomach Intestine. 1980;15:225-34.

26. Li C, Oh SJ, Kim S, Hyung WJ, Yan M, Zhu ZG, et al. Macroscopic Borrmann type as a simple prognostic indicator in patients with advanced gastric cancer. Oncology. 2009;77:197-204.

27. Raskin MM. Some specific radiological findings and consideration of linitis plastica of the gastrointestinal tract. CRC Crit Rev Clin Radiol Nucl Med. 1976;8:87-106.

28. Otsuji E, Kuriu Y, Okamoto K, Ochiai T, Ichikawa D, Hagiwara A, et al. Outcome of surgical treatment for patients with scirrhous carcinoma of the stomach. Am J Surg. 2004;188:327-32.

29. Ikeguchi M, Yamamoto O, Kaibara N. Management protocol for scirrhous gastric cancer. In Vivo. 2004;18:577-80.

30. Palli D, Bianchi S, Cipriani F, Duca P, Amorosi A, Avellini C, et al. Reproducibility of histologic classification of gastric cancer. $\mathrm{Br} J$ Cancer. 1991:63:765-8.

31. Chen YC, Fang WL, Wang RF, Liu CA, Yang MH, Lo SS, et al. Clinicopathological variation of Lauren classification in gastric cancer. Pathol Oncol Res. 2016;22:197-202.

32. Qiu MZ, Cai MY, Zhang DS, Wang ZQ, Wang DS, Li YH, et al. Clinicopathological characteristics and prognostic analysis of Lauren classification in gastric adenocarcinoma in China. J Transl Med. 2013;11:58.

33. Wirtzfeld D, Goldberg R, Savarese D. Hereditary diffuse gastric cancer. UpToDate, Post TW (Ed), UpToDate, Waltham, MA. Cited 11-11-14. Available from: URL: http://www.uptodate.com/contents/hereditary-diffuse-gastric-cancer. Accessed 22 May 2017

34. Lee JH, Chang KK, Yoon C, Tang LH, Strong VE, Yoon SS. Lauren histologic type is the most important factor associated with pattern of recurrence following resection of gastric adenocarcinoma. Ann Surg. 2016. [Epub ahead of print].

35. Stelzner S, Emmrich P. The mixed type in Lauren's classification of gastric carcinoma. Histologic description and biologic behavior. Gen Diagn Pathol. 1997;143:39-48

36. Adachi Y, Yasuda K, Inomata M, Sato K, Shiraishi N, Kitano S. Pathology and prognosis of gastric carcinoma: well versus poorly differentiated type. Cancer. 2000:89:1418-24.

37. Kwon KJ, Shim KN, Song EM, Choi JY, Kim SE, Jung HK, et al. Clinicopathological characteristics and prognosis of signet ring cell carcinoma of the stomach. Gastric Cancer. 2014;17:43-53.

38. Shim JH, Song KY, Kim HH, Han SU, Kim MC, Hyung WJ, et al. Signet ring cell histology is not an independent predictor of poor prognosis after curative resection for gastric cancer: a propensity analysis by the KLASS Group. Medicine (Baltimore). 2014;93:e136.

39. Taghavi S, Jayarajan SN, Davey A, Willis Al. Prognostic significance of signet ring gastric cancer. J Clin Oncol. 2012;30:3493-8.

40. Flucke U, Monig SP, Baldus SE, Zirbes TK, Bollschweiler E, Thiele J, et al. Differences between biopsy- or specimen-related Lauren and World Health Organization classification in gastric cancer. World J Surg. 2002;26:137-40.

41. Tan IB, Ivanova T, Lim KH, Ong CW, Deng N, Lee J, et al. Gastroenterology. 2011;141:476-85. 85 e1-11.

42. Cancer Genome Atlas Research N. Comprehensive molecular characterization of gastric adenocarcinoma. Nature. 2014;513:202-9.

43. Cristescu R, Lee J, Nebozhyn M, Kim KM, Ting JC, Wong SS, et al. Molecular analysis of gastric cancer identifies subtypes associated with distinct clinical outcomes. Nat Med. 2015:21:449-56.

44. Lei Z, Tan IB, Das K, Deng N, Zouridis H, Pattison S, et al. Identification of molecular subtypes of gastric cancer with different responses to PI3-kinase inhibitors and 5-fluorouracil. Gastroenterology. 2013;145:554-65. 
45. Corso S, Giordano S. How can gastric cancer molecular profiling guide future therapies? Trends Mol Med. 2016;22:534-44.

46. Endrullat C, Glokler J, Franke P, Frohme M. Standardization and quality management in next-generation sequencing. Appl Transl Genomics. 2016; 10:2-9.

47. Arnedos M, Soria JC, Andre F, Tursz T. Personalized treatments of cancer patients: a reality in daily practice, a costly dream or a shared vision of the future from the oncology community? Cancer Treat Rev. 2014;40:1192-8.

48. Rosai J, Ackermans. Surgical pathology. 9th ed. St Louis: Mosby; 2004.

49. Terai S, Fushida S, Tsukada T, Kinoshita J, Oyama K, Okamoto K, et al. Bone marrow derived "fibrocytes" contribute to tumor proliferation and fibrosis in gastric cancer. Gastric Cancer. 2015;18:306-13.

50. Naito Y, Sakamoto N, Oue N, Yashiro M, Sentani K, Yanagihara K, et al. MicroRNA-143 regulates collagen type III expression in stromal fibroblasts of scirrhous type gastric cancer. Cancer Sci. 2014;105:228-35.

51. Dvorak HF. Tumors: wounds that do not heal-redux. Cancer Immunol Res. 2015;3:1-11

52. Zeisberg EM, Potenta S, Xie L, Zeisberg M, Kalluri R. Discovery of endothelial to mesenchymal transition as a source for carcinoma-associated fibroblasts. Cancer Res. 2007;67:10123-8.

53. Yashiro M, Hirakawa K. Cancer-stromal interactions in scirrhous gastric carcinoma. Cancer Microenviron. 2010;3:127-35.

54. Inoue T, Chung YS, Yashiro M, Nishimura S, Hasuma T, Otani S, et al. Transforming growth factor-beta and hepatocyte growth factor produced by gastric fibroblasts stimulate the invasiveness of scirrhous gastric cancer cells. Jpn J Cancer Res. 1997;88:152-9.

55. Burgain C, Germain A, Bastien C, Orry X, Chone L, Claudon M, et al. Computed tomography features of gastrointestinal linitis plastica: spectrum of findings in early and delayed phase imaging. Abdom Radiol (NY). 2016; 41:1370-7.

56. Kanter MA, Isaacson NH, Knoll SM, Nochomovitz LE. The diagnostic challenge of metastatic linitis plastica. Two cases and a consideration of the problem. Am Surg. 1986;52:510-3

57. Ciulla A, Castronovo G, Tomasello G, Maiorana AM, Russo L, Daniele E, et al. Gastric metastases originating from occult breast lobular carcinoma: diagnostic and therapeutic problems. World J Surg Oncol. 2008:6:78.

58. El-Hage A, Ruel C, Afif W, Wissanji H, Hogue JC, Desbiens C, et al. Metastatic pattern of invasive lobular carcinoma of the breast-emphasis on gastric metastases. J Surg Oncol. 2016;114:543-7.

59. Thies $S$, Langer $R$. Tumor regression grading of gastrointestinal carcinomas after neoadjuvant treatment. Front Oncol. 2013;3:262.

60. Shabot JM, Roark GD, Brannan M, Patterson M. Endoscopic prognosis in gastric cancer. J Clin Gastroenterol. 1983;5:25-8.

61. Chiyo T, Kobara H, Mori H, Katsuki N, Haba R, Masaki T. Submucosal endoscopic sampling for indefinite gastric linitis plastica infiltrating into the submucosal layer. J Gastrointestin Liver Dis. 2015;24:375-8.

62. Ahn JB, Ha TK, Lee HR, Kwon SJ. An insufficient preoperative diagnosis of Borrmann type 4 gastric cancer in spite of EMR. J Gastric Cancer. 2011;11: 59-63.

63. Fasoli A, Pugliese V, Furnari M, Gatteschi B, Truini M, Meroni E. Signet ring cell carcinoma of the stomach: correlation between endocytoscopy and histology. Endoscopy. 2009;41 Suppl 2:E65-6.

64. Gong S, Ge ZZ, Xue HB. In vivo diagnosis of gastric signet-ring cell carcinoma by confocal laser endomicroscopy. J Dig Dis. 2014;15:46-9.

65. Chen CY, Jaw TS, Wu DC, Kuo YT, Lee CH, Huang WT, et al. MDCT of giant gastric folds: differential diagnosis. AJR Am J Roentgenol. 2010;195:1124-30.

66. Song $W$, Chen $C Y, X u J B$, Ye JN, Wang $L$, Chen CQ, et al. Pathological diagnosis is maybe non-essential for special gastric cancer: case reports and review. World J Gastroenterol. 2013;19:3904-10.

67. Choi J, Joo I, Lee JM. State-of-the-art preoperative staging of gastric cancer by MDCT and magnetic resonance imaging. World J Gastroenterol. 2014;20: 4546-57.

68. Kwee RM, Kwee TC. Imaging in local staging of gastric cancer: a systematic review. J Clin Oncol. 2007;25:2107-16.

69. Liu S, Guan W, Wang H, Pan L, Zhou Z, Yu H, et al. Apparent diffusion coefficient value of gastric cancer by diffusion-weighted imaging: correlations with the histological differentiation and Lauren classification. Eur J Radiol. 2014;83:2122-8.

70. Kodera Y, Nakanishi H, Ito S, Mochizuki Y, Yamamura Y, Fujiwara M, et al. Detection of disseminated cancer cells in linitis plastica-type gastric carcinoma. Jpn J Clin Oncol. 2004;34:525-31.
71. Ikoma N, Blum M, Chiang YJ, Estrella JS, Roy-Chowdhuri S, Fournier K, et al Yield of staging laparoscopy and lavage cytology for radiologically occult peritoneal carcinomatosis of gastric cancer. Ann Surg Oncol. 2016;23(13): 4332-7. Epub 2016 Jul 6.

72. Ichikawa Y, Koshikawa N, Hasegawa S, Ishikawa T, Momiyama N, Kunizaki C, et al. Marked increase of trypsin(ogen) in serum of linitis plastica (gastric cancer, borrmann 4) patients. Clin Cancer Res. 2000;6:1385-8.

73. Tsujiura M, Ichikawa D, Konishi H, Komatsu S, Shiozaki A, Otsuji E. Liquid biopsy of gastric cancer patients: circulating tumor cells and cell-free nucleic acids. World J Gastroenterol. 2014;20:3265-86.

74. Ueda T, Volinia S, Okumura H, Shimizu M, Taccioli C, Rossi S, et al. Relation between microRNA expression and progression and prognosis of gastric cancer: a microRNA expression analysis. Lancet Oncol. 2010;11:136-46.

75. Kodera Y, Ito S, Mochizuki Y, Yamamura Y, Misawa K, Ohashi N, et al. The number of metastatic lymph nodes is a significant risk factor for bone metastasis and poor outcome after surgery for linitis plastica-type gastric carcinoma. World J Surg. 2008;32:2015-20.

76. Aranha GV, Georgen R. Gastric linitis plastica is not a surgical disease. Surgery. 1989;106:758-62. discussion 62-3.

77. Hamy A, Letessier E, Bizouarn P, Paineau J, Aillet G, Mirallie E, et al. Study of survival and prognostic factors in patients undergoing resection for gastric linitis plastica: a review of 86 cases. Int Surg. 1999:84:337-43.

78. Thompson RJ, Ranaghan L, Kennedy R, Clements W, Carey PD, Kennedy JA. Survival following operative management of gastric linitis plastica compared with non-operative management. Ann R Coll Surg Engl. 2017; 99(3):228-32. Epub 2016 Nov 4

79. Rosenbaum PR, Rubin DB. The central role of the propensity score in observational studies for causal effects. Biometrika. 1983;70:41-55.

80. Japanese Gastric Cancer Association. Japanese gastric cancer treatment guidelines 2010 (ver. 3). Gastric Cancer. 2011;14:113-23.

81. Shin D, Park SS. Clinical importance and surgical decision-making regarding proximal resection margin for gastric cancer. World J Gastrointest Oncol. 2013;5:4-11.

82. Squires 3rd MH, Kooby DA, Poultsides GA, Pawlik TM, Weber SM, Schmidt $\mathrm{CR}$, et al. Is it time to abandon the $5-\mathrm{cm}$ margin rule during resection of distal gastric adenocarcinoma? A multi-institution study of the U.S. Gastric Cancer Collaborative. Ann Surg Oncol. 2015;22:1243-51.

83. Yonemura Y, Canbay E, Li Y, Coccolini F, Glehen O, Sugarbaker PH, et al. A comprehensive treatment for peritoneal metastases from gastric cancer with curative intent. Eur J Surg Oncol. 2016;42:1123-31.

84. Biondi A, Lirosi MC, D'Ugo D, Fico V, Ricci R, Santullo F, et al. Neo-adjuvant chemo(radio)therapy in gastric cancer: current status and future perspectives. World J Gastrointest Oncol. 2015;7:389-400.

85. Park SH, Sohn TS, Lee J, Lim DH, Hong ME, Kim KM, et al. Phase III trial to compare adjuvant chemotherapy with capecitabine and cisplatin versus concurrent chemoradiotherapy in gastric cancer: final report of the adjuvant chemoradiotherapy in stomach tumors trial, including survival and subset analyses. J Clin Oncol. 2015:33:3130-6.

86. Smalley SR, Benedetti JK, Haller DG, Hundahl SA, Estes NC, Ajani JA, et al. Updated analysis of SWOG-directed intergroup study 0116: a phase III trial of adjuvant radiochemotherapy versus observation after curative gastric cancer resection. J Clin Oncol. 2012;30:2327-33.

87. Messager M, Lefevre JH, Pichot-Delahaye V, Souadka A, Piessen G, Mariette $C$, et al. The impact of perioperative chemotherapy on survival in patients with gastric signet ring cell adenocarcinoma: a multicenter comparative study. Ann Surg. 2011;254:684-93. discussion 93.

88. Piessen G, Messager M, Le Malicot K, Robb WB, Di Fiore F, Guilbert M, et al. Phase II/III multicentre randomised controlled trial evaluating a strategy of primary surgery and adjuvant chemotherapy versus peri-operative chemotherapy for resectable gastric signet ring cell adenocarcinomas PRODIGE 19 - FFCD1103 - ADCI002. BMC Cancer. 2013:13:281.

89. Darakhshan S, Pour AB. Tranilast: a review of its therapeutic applications. Pharmacol Res. 2015;91:15-28.

90. Shinto O, Yashiro M, Kawajiri H, Shimizu K, Shimizu T, Miwa A, et al. Inhibitory effect of a TGFbeta receptor type-I inhibitor, Ki26894, on invasiveness of scirrhous gastric cancer cells. Br J Cancer. 2010;102:844-51.

91. Yashiro M, Shinto O, Nakamura K, Tendo M, Matsuoka T, Matsuzaki T, et al. Synergistic antitumor effects of FGFR2 inhibitor with 5-fluorouracil on scirrhous gastric carcinoma. Int J Cancer. 2010;126:1004-16. 